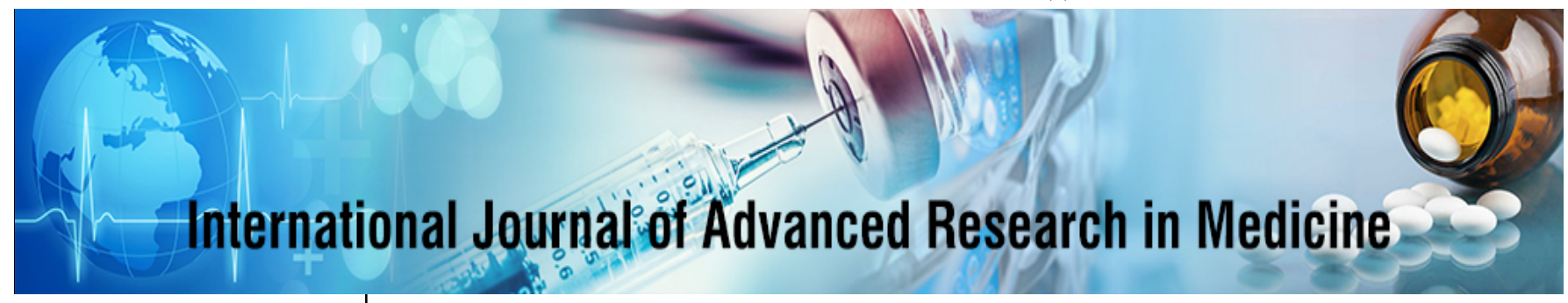

E-ISSN: 2706-9575

P-ISSN: 2706-9567

IJARM 2022; 4(1): 152-155

Received: 13-11-2021

Accepted: 04-01-2022

Suresh Kumar Bhargava

Professor, Department of Anaesthesia, National

Institute of medical science and research Jaipur,

Rajasthan, India

Dr. Neena Tiwari

Associate Professor,

Department of Anaesthesia,

National Institute of medical science and research Jaipur,

Rajasthan, India
Corresponding Author:

Dr. Neena Tiwari

Associate Professor,

Department of Anaesthesia,

National Institute of medical science and research Jaipur

Rajasthan, India

\section{The comparative study of intrathecal dexmedetomidine and fentanyl as adjuvants to bupivacaine}

\author{
Suresh Kumar Bhargava and Dr. Neena Tiwari
}

DOI: https://doi.org/10.22271/27069567.2022.v4.i1c.350

\begin{abstract}
Introduction: Spinal anaesthesia provided by bupivacaine may be to short for providing postoperative analgesia. This study is conducted for the understating and calculation of the efficacy of intrathecal fentanyl and intrathecal dexmedetomidine as an adjuvant to hyperbaric bupivacaine with regards to the onset duration of sensory and motor blockade.

Material \& Method: 200 patients were taken with difference age group and classified into two groups. Both group consist 100 patients and given spinal anaesthesia using bupivacaine $0.5 \%$, heavy $2.5 \mathrm{ml}$ with either fentanyl $25 \mu \mathrm{g}$ (group A) or $5 \mu$ g of preservative free dexmedetomidine (group B).

Result: During sedation we take proper measurement of major vital organ such as taken pulse rate, respiratory rate, blood pressure, and arterial oxygen saturation were obtained. After operation patient analgesia time were recorded.
\end{abstract}

Keywords: Bupivacaine, dexmedetomidine, fentanyl, spinal anaesthesia

\section{Introduction}

Spinal anesthesia is one of the most common anesthetic procedures in lower limb and also in lower abdomen surgery, most commonly it used because of its easy to administer ${ }^{[1]}$. There is some advantage of this method including patients wakefulness, rapid onset effect low failure rate, low-dose drug, desirable sensory and motor blocks and affordability ${ }^{[2]}$. Spinal anesthesia also showing some side effects like hypotension, bradycardia, nausea, vomiting. For reducing side effect it is possible giving to lay the patient in the lateral position and rotate the bevel of needle to the bottom and inject the hyperbaric local anesthetics slowly for its turbulent movement of the local anesthetics in the CSF ${ }^{[3]}$. The addition of fentanyl to hyperbaric bupivacaine improves the quality of intraoperative and early postoperative subarachnoid block ${ }^{[4]}$. The identification of opioid receptors in the spinal cord can proved the potent analgesic effects of neuraxial opioids which have been exploited to improve perioperative analgesia and it reduce the supraspinal side effects of sedation and respiratory depression seen with systemic opioids ${ }^{[5]}$. However the addition of opioids in local anesthetic solution did not showing any advantages, like pruritus and respiratory depression. Dexmedetomidine, a new highly selective $\alpha 2$ - agonist, it is under evaluation as a neuraxial adjuvant for provides stable hemodynamic conditions, good quality of intraoperative and prolonged postoperative analgesia and it showing less side effects ${ }^{[6]}$. It has been approved by FDA as a short-term sedative for mechanically ventilated for intensive care unit patients [7]. Fentanyl is a synthetic, lipophilic phenylpiperidine opioid agonist with an analgesic which showing anesthetic properties. Fentanyl selectively binds and it activates the mureceptor in the central nervous system and it start mimicking the effects of endogenous opiates. The Activation of the mu-subtype opioid receptor stimulates the exchange of GTP for GDP on the G-protein complex and it subsequently inhibits the action of adenylate cyclase. Due to which there are decrease in intracellular cAMP which inhibits cAMPmediated and it affect calcium influx into the cell via the calcium channels due to which there is the hyperpolarization take place and it reduced neuronal excitability ${ }^{[8]}$. There were very few studies found in which comparing between intrathecal dexmedetomidine and fentanyl as adjuvants to hyperbaric bupivacaine. In such case we need some study for knowing the best effective anesthetic drug for lower abdomen and lower limb surgery.

\section{Materials and Methods}

The present study was conducted in Anesthesia department at National Institute of medical science and research Jaipur Rajasthan 
There was total 200 patient were taken for the study. All patient were divided in to 2 group each group consist 100 patient and name of the group1 \& group 2.

Group 1(100) patients received $2.5 \mathrm{~mL}$ volume of $0.5 \%$ hyperbaric bupivacaine with $25 \mathrm{~g}$ fentanyl intrathecally and Group 2(100) $(n=50)$ received $2.5 \mathrm{~mL}$ volume of $0.5 \%$ hyperbaric bupivacaine and 5gdexmedetomidine in $0.5 \mathrm{~mL}$ of normal saline intrathecal (dexmedetomidine $100 \mathrm{~g} / \mathrm{mL}$ was diluted in $10 \mathrm{ml}$ preservative-free normal saline). Duration of study period was may 2021to December 2021.

\section{Given parameters were noted:}

1. Onset of sensory blockade and motor blockade.

2. Total duration of analgesia noted.

3. Side effects if any are noted.

Haemodynamic monitoring was done regularly in every short interval of time till the end of surgery and it was also observed post operatively.

These parameter were Monitoring

1. Mean arterial pressure (MAP),

2. SpO2 hourly.

3. Systolic blood pressure (SBP)

4. ECG

5. Diastolic blood pressure (DBP),

6. Heart rate (HR),

For the Sensory Blockade: we will calculated time taken from the completion of the injection till then the patient does not complaining any pain.

Time Taken for Maximum Sensory Blockade: it can be defined as for drug for maximum sensory blocked.
Duration of Analgesia: it can be defined as the time duration in complete injection of drug to reduced pain for post -operative period.

It is measure by Analogue Scale Score on a $10 \mathrm{~cm}$ scale:

1. Grade 0:0 No pain.

2. Grade 1:1-2.5 Mild Pain.

3. Grade 2:2.6-5 Moderate Pain.

4. Grade 3:5.1-7.5 Severe Pain.

5. Grade 4:7.6-10 Worst possible pain.

Duration of Sensory Blockade: the time duration between injection till the patient loss its complete recovery from the sensation loss.

Duration of Motor Blockade: the time duration between patient for attains complete motor recovery.

Statistical Analysis: Statistical analysis was performed by using computer based software, Statistical Package for Social Science (SPSS).

\section{Observation and Results}

The all patients were divided in to 2 groups 1 \& 2 by randomized computer selection and it divided patients in to group, group 1 and group 2. Group 1 (100) received 2.5mL volume of $0.5 \%$ hyperbaric bupivacaine with $25 \mathrm{~g}$ fentanyl intrathecally and Group (100) received $2.5 \mathrm{~mL}$ volume of $0.5 \%$ hyperbaric bupivacaine and 5gdexmedetomidine in $0.5 \mathrm{~mL}$ of normal saline intrathecal (dexmedetomidine $100 \mathrm{~g} / \mathrm{mL}$ was diluted in $10 \mathrm{ml}$ preservative-free normal saline).

Table 1: Showing the mean difference between group 1 and group 2 patients

\begin{tabular}{|c|c|c|}
\hline & Group 1 & Group 2 \\
\hline Age year & 42 & 48 \\
\hline Height & 164 & 170 \\
\hline Weight & 70 & 75 \\
\hline Duration of Surgery & 190 & 192 \\
\hline Hysterectomy & 10 & 20 \\
\hline Inguinal hernia & 20 & 30 \\
\hline Urinary bladder and ureteric surgery & 30 & 10 \\
\hline Cholecystectomy & 40 & 40 \\
\hline
\end{tabular}

Table 2: Showing Feature of sensory block

\begin{tabular}{|c|c|c|}
\hline & Group 1 & Group 2 \\
\hline Highest sensory level & T5 (T4-T8) & T5 (T4-T8) \\
\hline Time from injection to highest sensory- level (min) & $11.3 \pm 1.8$ & $11.3 \pm 1.8$ \\
\hline Time of two segment regression from the highest $118 \pm 10$ sensory- level (min) & $120 \pm 10$ & $70 \pm 10$ \\
\hline Time of segment regression to S1 from the highest $470 \pm 10$ sensory- level (min) & $450 \pm 9$ & $145 \pm 10$ \\
\hline Total analgesic dose in first 24h (mg) & $80 \pm 12$ & $195 \pm 40$ \\
\hline Time to rescue analgesia (min) & $220 \pm 10$ & $150 \pm 45$ \\
\hline Onset to bromage 3 (min) & $12 \pm 45$ & $12 \pm 45$ \\
\hline Regression to Bromage 0 (min) & $500 \pm 10$ & $200 \pm 40$ \\
\hline
\end{tabular}

Table 3: Showing the mean sedation score

\begin{tabular}{|c|c|}
\hline \multicolumn{2}{|c|}{ Mean sedation score } \\
\hline Group 1 & 4.2 \\
\hline Group 2 & 3.1 \\
\hline
\end{tabular}




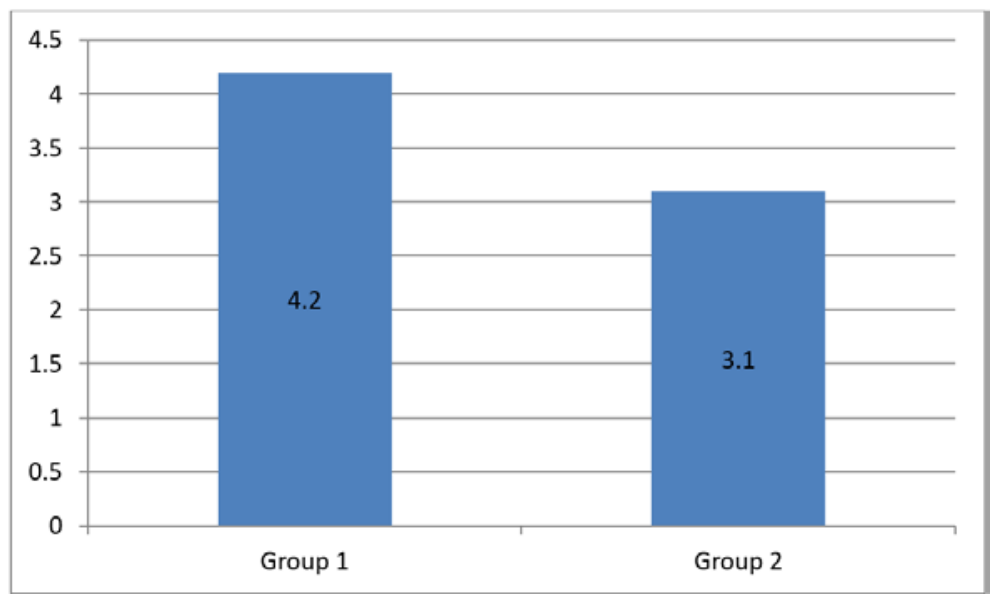

Bar graph 1: showing the mean sedation score in both group 1 \& group 2

Table 4: Showing the side effects in both group

\begin{tabular}{|c|c|c|}
\hline & Group 1 & Group 2 \\
\hline Nausea & 10 & 15 \\
\hline Vomiting & 5 & 6 \\
\hline pruritus & 1 & 4 \\
\hline Respiratory depression & 2 & 4 \\
\hline Hypotension & 1 & 4 \\
\hline Bradycardia & 1 & 6 \\
\hline Urinary retention & 1 & 1 \\
\hline
\end{tabular}

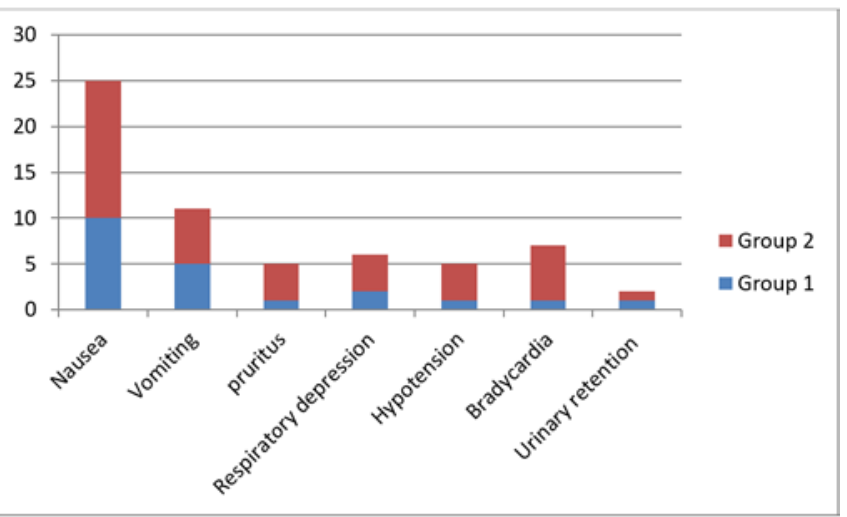

Bar graph 2: Showing the side effects in both group.

\section{Discussion}

The mechanism of spinal anesthetic is not well understand but they act on binding to presynaptic C - fibres and postsynaptic dorsal horn neuron which causes motor and sensory block. There are many known analgesic action is but most of do depression by release of c- fibres transmitters and hyperpolarisation of the postsynaptic dorsal horn neurons ${ }^{[9]}$. Local anesthetic works as the blocking of sodium channels which act as prolong effect this showing by the synergism between local anesthetic and $\alpha 2$ adrenoceptor agonist, while the prolongation of the motor block in spinal anesthetics may result from the binding of a2- adrenoceptor agonists in motor neurons in the dorsal horn ${ }^{[10]}$. Fukushima et al. they administered $2 \mu \mathrm{g} / \mathrm{kg}$ epidural dexmedetomidine for postoperative analgesia in humans but did not report any neurologic deficits ${ }^{[11]}$. While in our study we add $5 \mu \mathrm{g}$ dexmedetomidine with hyperbaric bupivacaine significantly prolongs both sensory and motor block and we find Both fentanyl and dexmedetomidine provided good quality intraoperative analgesia and hemodynamic stability. The analgesia was clinically better in group $\mathrm{A}$ as compared to group B. Small doses of intrathecal dexmedetomidine $(3 \mu \mathrm{g})$ used in combination with bupivacaine in humans have been shown to shorten the onset of motor block and prolong the duration of motor and sensory block with hemodynamic stability and they show lack of sedation also ${ }^{[7]}$. Al-Ghanem et al. had studied and show the effect on addition of $5 \mu \mathrm{g}$ dexmedetomidine or 25 $\mu \mathrm{g}$ fentanyl intrathecal to $10 \mathrm{mg}$ isobaric bupivacaine in vaginal hysterectomy and found that $5 \mu \mathrm{g}$ dexmedetomidine produces more prolonged motor and sensory block as compared with $25 \mu \mathrm{g}$ fentanyl ${ }^{[12]}$. While comparing with our study we found group a has longer duration of both sensory and motor blockade stable hemodynamic condition, and good patient satisfaction. Al-Mustafa et al. studied and observed that dexmedetomidine 5 and $10 \mu \mathrm{g}$ with bupivacaine in urological procedures and found that dexmedetomidine prolongs the duration of spinal anesthesia in a dose-dependent manner ${ }^{[13]}$. Bogra $\mathrm{J}$ et al. studied and observed that Visceral pain usually occurs during abdominal surgery under spinal anesthesia but while adding the Intrathecal fentanyl in local anesthetics reduces visceral and somatic pain ${ }^{[14]}$. In both group A and B patient not showing any perceived visceral pain.

\section{Conclusion}

$5 \mu \mathrm{g}$ dexmedetomidine seems to be a very good alternative to $25 \mu \mathrm{g}$ fentanyl as an adjuvant to spinal bupivacaine in surgical procedures. It provides a good quality of intraoperative analgesia, hemodynamically stable conditions, minimal side effects, and excellent quality of postoperative analgesia. Such more study need for knowing more about drug and its effect.

\section{Reference}

1. Elia N, Culebras X, Mazza C, Schiffer E, Tramèr MR. Clonidine as an adjuvant to intrathecal local anesthetics for surgery: Systematic review of randomized trials. Reg Anesth Pain Med. 2008;33:159-67.

2. Henke VG, Bateman BT, Leffert LR. Focused review: spinal anesthesia in severe preeclampsia. Anesth Analg. 2013;117:686-93.

3. Henke VG, Bateman BT, Leffert LR. Focused review: spinal anesthesia in severe preeclampsia. Anesth Analg. 2013;117:686-93.

4. Casati A, Moizo E, Marchetti C, et al. A prospective, rando- mized, double-blind comparison of unilateral spinal anesthesia with hyperbaric bupivacaine, 
ropivacaine, or levobupivacaine for inguinal herniorrhaphy. Anesth Analg. 2004;99:1387-92.

5. Hunt CO, Naulty JS, Bader AM, Hauch MA, Vartikar JV, Datta S, et al. Perioperative analgesia with subarachnoid fentanyl-bupivacaine for Cesarean delivery. Anesthesiology. 1989;71:535-40.

6. Etches RC, Sandler AN, Daley MD. Respiratory depression and spinal opiods. Can J Anaesth. 1989;36:165-85.

7. Al-Ghanem SM, Massad IM, Al-Mustafa MM, AlZaben KR, Qudaisat IY, Qatawneh AM, et al. Effect of Adding Dexmedetomidine versus Fentanyl to Intrathecal Bupivacaine on Spinal Block Characteristics in Gynecological Procedures: A Double Blind Controlled Study. Am J Appl Sci. 2009;6:882-7.

8. Kanazi GE, Aouad MT, Jabbour-Khoury SI, Al Jazzar $\mathrm{MD}$, Alameddine MM, Al- Yaman R, et al. Effect of low-dose dexmedetomidine or clonidine on the characteristics of bupivacaine spinal block. Acta Anesthesiol Scand. 2006;50:222-7. https://pubchem.ncbi.nlm.nih.gov/compound/fentanyl.

9. Eisenach JC, De Kock M, Klimscha W. $\alpha 2$-Adrenergic Agonists for Regional Anesthesia: A Clinical Review of Clonidine (1984 - 1995) Anesthesiology. 1996;85:655-74.

10. Harada Y, Nishioka K, Kitahata LM, Kishikawa K, Collins JG. Visceral antinociceptive effects of spinal clonidine combined with morphine, enkephalin, or U50, 488H. Anesthesiology. 1995;83:344-52.

11. Fukushima K, Nishimi Y, Mori K, Takeda J. Effect of epidurally administered dexmedetomidine on sympathetic activity and postoperative pain in man. Anesth Analg. 1996;82:S121.

12. Al-Ghanem SM, Massad IM, Al-Mustafa MM, AlZaben KR, Qudaisat IY, Qatawneh AM, et al. Effect of Adding Dexmedetomidine versus Fentanyl to Intrathecal Bupivacaine on Spinal Block Characteristics in Gynecological Procedures: A Double Blind Controlled Study. Am J Appl Sci. 2009;6:882-7.

13. Al-Mustafa MM, Abu-Halaweh SA, Aloweidi AS, Murshidi MM, Ammari BA, Awwad ZM, et al. Effect of dexmedetomidine added to spinal bupivacaine for urological procedure. Saudi Med J. 2009;30:365-70.

14. Bogra J, Arora N, Srivastava P. Synergistic effect of intrathecal fentanyl and bupivacaine in spinal anaesthesia for cesarean section. BMC Anesthesiol. 2005;5:5. 